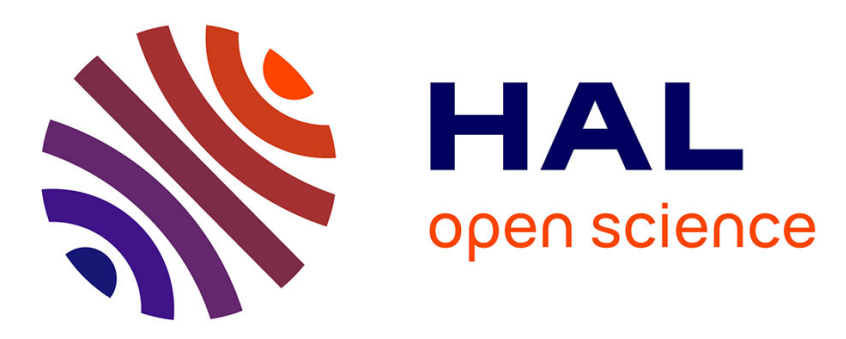

\title{
Gas Permeability measurement on injected soils with cement grout
}

\author{
Nadia Saiyouri, Marwen Bouasker, Abdelhafid Khelidj
}

\section{To cite this version:}

Nadia Saiyouri, Marwen Bouasker, Abdelhafid Khelidj. Gas Permeability measurement on injected soils with cement grout. Cement and Concrete Research, 2007, 38 (1), pp.95-103. 10.1016/j.cemconres.2007.08.015 . hal-01006910

\section{HAL Id: hal-01006910 https://hal.science/hal-01006910}

Submitted on 8 Jun 2018

HAL is a multi-disciplinary open access archive for the deposit and dissemination of scientific research documents, whether they are published or not. The documents may come from teaching and research institutions in France or abroad, or from public or private research centers.
L'archive ouverte pluridisciplinaire HAL, est destinée au dépôt et à la diffusion de documents scientifiques de niveau recherche, publiés ou non, émanant des établissements d'enseignement et de recherche français ou étrangers, des laboratoires publics ou privés. 


\title{
Gas permeability measurement on injected soils with cement grout
}

\author{
N. Saiyouri, M. Bouasker, A. Khelidj \\ GeM, Research Institute in Civil Engineering and Mechanics UMR CNRS 6183. Ecole Centrale de Nantes, Nantes University, IUT de Saint Nazaire, France
}

This paper deals with cement grout injection and its consequences in porous media from an experimental point of view. This injection with very fine cement has to reinforce the medium considered which is a sand extracted from the Loire river (in the west of France). To quantify this improvement phenomenon, measurement of the conductivity decreases after the injection operation is proposed. Injected sand columns are prepared and gas conductivity measurement is done. The aim of this paper is to show gas conductivity results and their interpretation and effects on the injected medium evolution. These demonstrate the very strong decrease between intrinsic conductivity values before and after injection. The reduction ratio is about $10^{-4}$. This allows evaluation of the sample porosity reduction and then the filtration phenomenon. This is responsible for pressure and cement deposition increase in the system voids during soil injection.

Keywords: Grout injection; Gas conductivity; Intrinsic permeability; Improvement of soil; Experimental device

\section{Introduction}

Injection is one of the most widely used techniques of soil stabilization. Indeed, it is an inexpensive technique which can achieve several purposes: sealing, prevention and protection of the foundations as well as the improvement of the mechanical characteristics of the injected medium. This technique consists of injecting the ground under pressure with a fluid which is propagated in the medium and solidified.

The grout thus combines with the ground, thereby presenting better mechanical characteristics. The ground reinforcement process by injection has undergone an important evolution during these last years. Two aspects are studied: modeling of grout propagation and understanding of the injected soil mechanical behavior. Nevertheless, grout transport in the porous environment still remains poorly controlled because of many phenomena such as filtration [1-3]. In order to characterize the process, it is important to know how the fluid is propagated in the ground, and how the medium porosity is reduced [4]. These two parameters are the essential bases for the optimization of the technique and the success of the injection operation at a reasonable cost. In this paper, we will try to answer the second question by studying the

\footnotetext{
* Corresponding author. Tel.: +332403716 61; fax: +33240372535.
} E-mail address: nadia.saiyouri@ec-nantes.fr (N. Saiyouri). gas permeability to have an idea of the evolution of porosity after the injection compared to the initial porosity of the sample.

To achieve this, the procedures of sand compaction in the columns which allow us to fix the desired density are first studied. Once these procedures are defined, a study of the permeability to water is made on samples of various densities. After having characterized the medium to be injected, a characterization of the grout used is also needed. This is achieved by rheological measurements which enable us to define the behavior law of the grout. The mean parameters which can be controlled by knowing the behavior law of the grout are: the setting time, the viscosity and the concentration.

The setting time is a very important parameter in the injection process. The grout has to set quickly after injection in order to be sufficiently rigid. Cements have setting times which generally range between 4 and $5 \mathrm{~h}$. However, in the case of strongly diluted cements, the setting is simply delayed $10 \mathrm{~h}$.

The second important parameter is the viscosity, which varies according to the cement concentration and the plasticizer (or chemical mixture) amount. Knowing the viscosity gives very good indications of the injectivity of the grout. Generally, grouts of viscosity lower than $2 \mathrm{mPa}$ s can penetrate the ground without modifying its structure. Time and viscosity are strongly related for grout cements. An example of the viscosity variation according to time is given for a standard bentonite cement grout [5]. 
Table 1

Procedure of sand column preparation (thickness of each layer is $10 \mathrm{~cm}$ )

\begin{tabular}{|c|c|c|c|c|c|}
\hline Procedure & A & B & $\mathrm{C}$ & $\mathrm{D}$ & $\mathrm{E}$ \\
\hline Top & \multirow{10}{*}{ 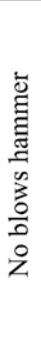 } & 3 & 3 & 18 & 75 \\
\hline \multirow{8}{*}{$1 \mathrm{~m}$} & & & 3 & 18 & \\
\hline & & 3 & 4 & 19 & \\
\hline & & & 4 & 19 & \\
\hline & & 3 & 5 & 20 & \\
\hline & & & 5 & 20 & \\
\hline & & 3 & 6 & 21 & \\
\hline & & & 6 & 21 & \\
\hline & & 3 & 7 & 22 & \\
\hline Bottom $\Downarrow$ & & & 7 & 22 & \\
\hline
\end{tabular}

The ratio between the first and the last viscosity value can be about 2 (in Marsh units); between 16 and $30 \mathrm{~h}$.

The third parameter is the concentration. Grout viscosity is also a function of the different component concentrations. The water-to-cement ratio (W/C) remains, however, the basic variable which influences its properties. Other authors (Einstein [6], Guth [7] and Brinkman [8]) proposed several expressions of the rheological parameters versus concentration.

Several injection tests are carried out in order to understand the propagation mechanism of the grout in the sand. The major objective of this study is to characterize the medium injected by measuring gas permeability to assess the contribution of the injection to the void reduction in the medium. Permeability will be studied according to several parameters such as the water content of the samples and the height considered in the column [9].

\section{Materials and methods}

\subsection{Sand columns preparation}

The major problem while preparing the sand columns is to obtain the desired density. Currently, there is no device which allows a precise regulation of the density except the methods which are based on compaction using hammer blows or ramming. According to Yin [10], a relation is established between the sand porosity and the densification procedure in the column. The columns used are made of transparent PVC or rigid Plexi- glas of $1000 \mathrm{~mm}$ height and $100 \mathrm{~mm}$ of internal diameter. The sand used is a Loire sand, the grain size of which can vary between $0-2 \mathrm{~mm}$ and $\gamma_{\min }=15.07 \mathrm{kN} / \mathrm{m}^{3}, \gamma_{\max }=18.52 \mathrm{kN} / \mathrm{m}^{3}$.

In order to obtain different densities, various numbers of plastic hammer blows are applied to the column. Thus, several procedures (A to E) are developed (Table 1).

\subsection{Water conductivity of sand columns}

Measurements of water conductivity are achieved on Loire sand samples with different densities. The standard NFP 94-090-1 [11] is applied by using a classical constant head permeameter device. The expected results are obtained with Darcy's law.

\subsection{Grout rheology}

Before sand injection operations, cement grout rheology is studied. The used cement is a Spinor A12, from Origny (near Paris) with 2.94 of grain density. A coaxial cylinder rheometer (rheomat 115) is used [12]. This allows us to determine the viscosity and therefore the rheological behavior of the grout $[13,14]$.

The grout studied is prepared by mixing the following components at $100 \mathrm{tr} / \mathrm{min}$ : water, inert load (chalk with maximum particle size of $1 \mu \mathrm{m}$, and 2.71 of grain density), cement, and plasticizer. The grout formulation (see Table 2) was varied to study the effects of superplasticizer content, and inert load (chalk). It is important to note here that the ratio between the dry matter and water $\mathrm{W} /(\mathrm{C}+$ inert load $)$ is mentioned for every formulation. Segregation or bleeding tests are used to verify the obtained grout stability for each formulation. The influence of time and temperature were also studied, essentially to determine the period of grout use $[15,16]$.

\subsection{Grout cement injection in the sand}

The injections are made on PVC columns filled with Loire sand at different densities and water to cement ratios for the grout. The injection device (Fig. 1) consists of a variable flow pump (Milroyal B) and a mixer (Rayneri Turbotest) with a speed range between 0 and $3000 \mathrm{rpm}$. The PVC columns are of

Table 2

Grout formulations

\begin{tabular}{|c|c|c|c|c|c|c|c|}
\hline Composition & $\mathrm{W} / \mathrm{C}$ & $\mathrm{W} / \mathrm{C}+$ inert load & Water & Cement (SpinorA12) & Inert load & Plasticizer & Density \\
\hline Units & - & & $\mathrm{ml}$ & $\mathrm{g}$ & $\mathrm{g}$ & $\mathrm{ml}$ & $\mathrm{Kg} / \mathrm{l}$ \\
\hline \multirow[t]{4}{*}{ Grout 1} & 3.57 & 1.38 & 1350 & 375 & 600 & 10 & - \\
\hline & 3.57 & 1.38 & 1350 & 375 & 600 & 15 & 1.36 \\
\hline & 3.57 & 1.74 & 1350 & 375 & 400 & 15 & - \\
\hline & 3.57 & 1.15 & 1350 & 375 & 800 & 15 & - \\
\hline Grout 2 & 2.38 & 1.16 & 1350 & 562.5 & 600 & 10 & - \\
\hline \multirow[t]{3}{*}{ Grout 3} & 1.78 & 1.00 & 1350 & 750 & 600 & 10 & - \\
\hline & 1.78 & 1.00 & 1350 & 750 & 600 & 15 & 1.46 \\
\hline & 1.78 & 1.00 & 1350 & 750 & 600 & 20 & - \\
\hline
\end{tabular}

Injected column composition 


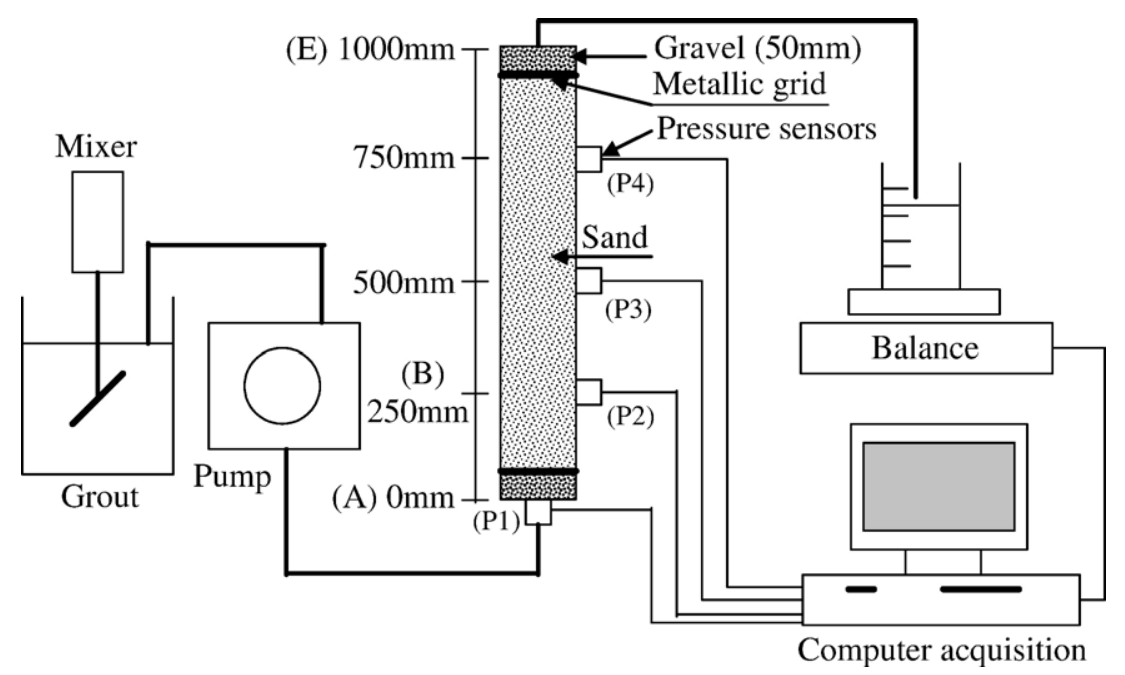

Fig. 1. Injected column flow sheet.

$1000 \mathrm{~mm}$ in height, $5 \mathrm{~mm}$ in thickness and $100 \mathrm{~mm}$ in inner diameter. On both sides of the column there is a $4 / 8 \mathrm{~mm}$ gravel layer, $50 \mathrm{~mm}$ thick separated from the ground by a sieve of suitable mesh $(210 \mu \mathrm{m})$, to ensure laminar grout flow. To ensure sealing during injection, two steel base plates are placed at the bottom and the top of the sample and are firmly fixed by threaded rods which prevent deformations of the sample.

Four pressure sensors $0-1000 \mathrm{kPa}$ are placed on the sand column at respective heights of $0 \mathrm{~mm}, 250 \mathrm{~mm}, 500 \mathrm{~mm}$ and $750 \mathrm{~mm}$.

The sand columns prepared with the desired density are first saturated with water. This will enable us to compare the experimental results with those of the numerical modeling, which is based on the assumption of water-saturated soils $[17,18]$. Then, the cement grout prepared according to the desired viscosity is injected. During injection tests, the following measurements are done: pressures throughout the column by means of the pressure sensors fitted, mass and volume of the fluid flowing out of the column, front injection advancement and time saturation with the grout. Then the columns are stored in a wet chamber.

\subsection{Gas permeability test procedure}

Intrinsic permeability is measured using a Cembureau constant head permeameter with nitrogen as the neutral percolating

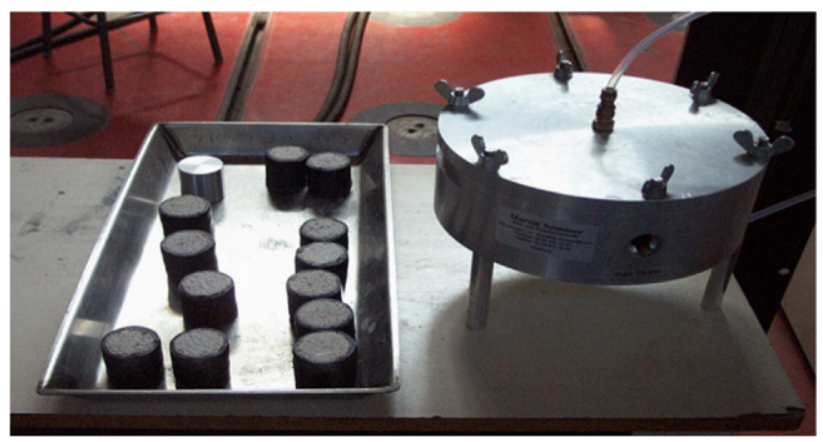

Fig. 2. Prepared samples with the permeability cell. gas $[19,20]$. The relative pressure $\left(P_{i}-P_{\mathrm{atm}}\right)$ applied to the sample, which ranges between 0 and $0.3 \mathrm{MPa}$, is read using a digital pressure gauge with an accuracy of $100 \mathrm{~Pa}$. Each disc is tested at five differential pressures: $0.05,0.1,0.15,0.2$ and $0.3 \mathrm{MPa}$. Establishing steady state flow as mentioned by other authors [20], for concrete samples, can take significant time (varying from $30 \mathrm{~min}$ to several hours). This condition is verified by taking two measurements separated by a 10 minute time interval. If two values differ by less than $2 \%$, the steady state flow condition is assumed to be achieved. This takes less time for injected soils (10 to $50 \mathrm{~min}$ ). For each differential pressure, the apparent coefficient of permeability $\mathrm{k}_{\mathrm{A}}\left(\mathrm{m}^{2}\right)$ is calculated from the Hagen-Poiseuille relationship, Eq. (1), for laminar flow of a compressible viscous fluid through a porous body [20].

$k_{A}=\frac{Q}{A} \cdot \frac{2 \mu \cdot L \cdot P_{\mathrm{atm}}}{\left(P_{i}^{2}-P_{\mathrm{atm}}^{2}\right)}$

$\mathrm{L}$ : thickness of the sample (m), A: cross-sectional area $\left(\mathrm{m}^{2}\right), \mathrm{Q}$ : measured gas flow $\left(\mathrm{m}^{3} / \mathrm{s}\right), \mu$ : viscosity coefficient $\left(1.7610^{-5} \mathrm{~Pa} \mathrm{~s}\right.$ for nitrogen gas at $\left.20^{\circ} \mathrm{C}\right), P_{i}$ : inlet pressure, i.e. applied absolute pressure $(\mathrm{Pa}), P_{\text {atm }}$ : atmospheric pressure $(\mathrm{Pa})$.

In fact, gas percolation through a fine porous body like injected sand can be regarded as resulting from two flow modes: viscous flow and slip flow or Knudsen flow. There are various methods of calculating the non-viscous flow. The most widely used is the relationship proposed by Klinkenberg, Eq. (2), which

Table 3

Injected columns characteristics

\begin{tabular}{llll}
\hline Injection & W/C & Density & Porosity \\
\hline $\mathrm{I}$ & 2.38 & 18.19 & 0.306 \\
$\mathrm{~J}$ & 2.38 & 17.20 & 0.344 \\
$\mathrm{~K}$ & 2.38 & 17.24 & 0.342 \\
$\mathrm{~L}$ & 2.38 & 18.14 & 0.308 \\
$\mathrm{M}$ & 3.57 & 18.06 & 0.311 \\
$\mathrm{~N}$ & 3.57 & 17.30 & 0.340 \\
\hline
\end{tabular}


Table 4

Average densities obtained by the various procedures and permeabilities

\begin{tabular}{|c|c|c|c|c|c|c|c|c|}
\hline Procedure & Average density $\mathrm{KN} / \mathrm{m}^{3}$ & $\mathrm{~K}\left(10^{-4} \mathrm{~m} / \mathrm{s}\right)$ & $n$ & $e$ & $I_{d}(\%)$ & $\gamma_{1}$ & $\gamma_{2}$ & $\gamma_{3}$ \\
\hline 0 & 15.07 & - & 0.425 & 0739 & & & & \\
\hline A & 15.48 & - & 0.409 & 0693 & 14.1 & 15.57 & 15.55 & 15.56 \\
\hline B & 16.65 & - & 0.365 & 0574 & 50.8 & 16.69 & 16.66 & 16.66 \\
\hline $\mathrm{C}($ Column 1) & 17.09 & 2.57 & 0.348 & 0.533 & 63.5 & 16.98 & 16.87 & 16.82 \\
\hline D (Column 2) & 17.81 & 2.04 & 0.320 & 0.471 & 82.5 & 17.52 & 17.48 & 17.47 \\
\hline E (Column 3) & 18.31 & 1.55 & 0.301 & 0.431 & 95.0 & 18.08 & 18.02 & \\
\hline
\end{tabular}

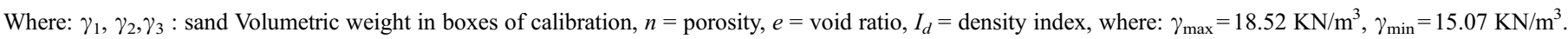

introduces the notion of an intrinsic coefficient of permeability $k_{V}\left(\mathrm{~m}^{2}\right)$ relative to viscous flow only.

$k_{A}=k_{V}\left(1+\frac{b}{P_{m}}\right)$

$P_{m}$ : mean gas pressure, $P_{m}=\left(P_{i}+P_{\text {atm }}\right) / 2$, b: Klinkenberg coefficient $(\mathrm{Pa})$

$k_{V}$ is the limiting value of gas permeability when the mean pressure $P_{m}$ tends toward infinity. The determination of $k_{V}$ consists of measuring $k_{A}$ at different pressures $\left(P_{i}\right)$ and in plotting it versus the inverse of the mean pressure $\left(1 / P_{m}\right)$. From the five applied differential pressures, the correlations of the linear regressions are satisfactory with a coefficient higher than 0.99 , [9.20]. The permeability is therefore regarded as the intrinsic gas permeability $k_{V}$ determined in Eq. (2) and depending on the water saturation degree of the injected sand tested $[9,20]$.

The apparent permeability depends on the atmospheric pressure which is measured with a Torricelli barometer $(1 \mathrm{hPa}$

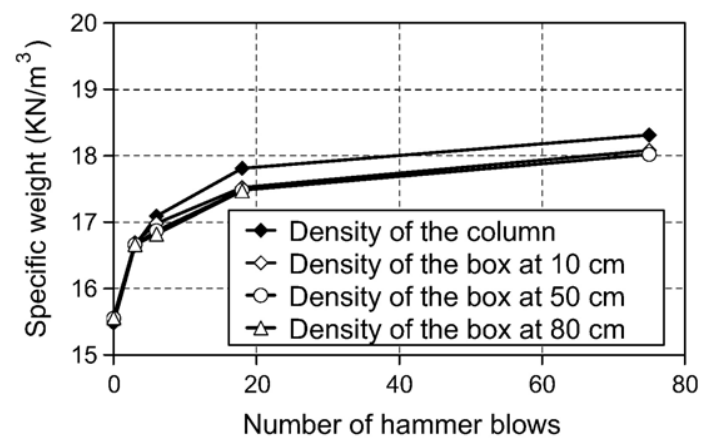

Fig. 3. Density versus applied number of blows.

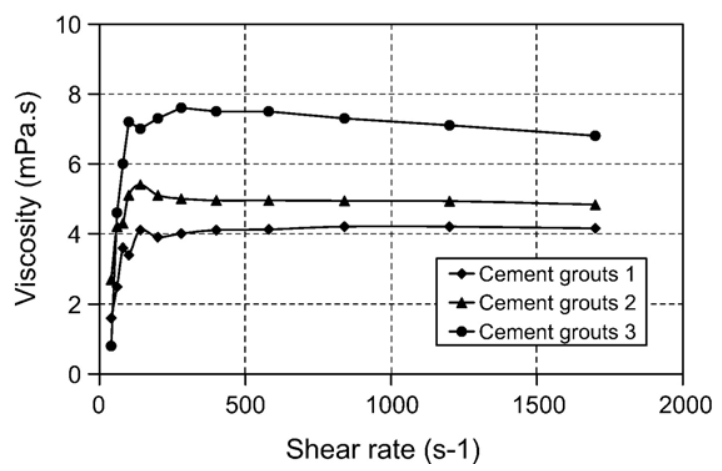

Fig. 4. Viscosity vs. Shear rate for grout $1,2,3\left(T=20^{\circ} \mathrm{C} ; t=2 \mathrm{mn}\right)$. precision). The sample is prepared by extraction of a disc $50 \mathrm{~mm}$ in diameter and height, from the injected sand column. This is done by using a core sampling tool $50 \mathrm{~mm}$ in internal diameter. Water is used to lubricate the coring tool and the samples are humidified. The circular face is surrounded by a thermo-retractable membrane (Fig. 2). The samples are dried in a climatic chamber with a regulated temperature at $60{ }^{\circ} \mathrm{C}$ and a relative humidity of $50 \%$. The $60{ }^{\circ} \mathrm{C}$ temperature is chosen to guarantee the stability of the thermo-retractable membrane and to avoid the fusion of its internal surface. The upper and lower surfaces of the disc are polished to be parallel and plane. The two faces are in contact with a striated plate allowing a homogeneous pressure distribution. The sample is put in a soft PVC fitted collard, by a tire tube pressurized at $0.7 \mathrm{MPa}$.

The gas permeability tests are carried out with various differential pressures. Four injection pressures, at least, are applied, so as to obtain a satisfactory measuring accuracy. The gas outputs are measured with atmospheric pressure using a volumetric flow-meter in accordance with the recommendation standard AFREM [21,22]. For each pressure of gas injection, five or six flow measurements are taken. Table 3 summarizes the injected column characteristics. The columns are cut into three sections. The references given to each sample is composed respectively by the number of the column Section $(1,2$ and 3 from the bottom of the column), the injection reference and the sample number.

\section{Results and analysis}

\subsection{Compacting procedure results, sample densities}

Table 4 summarizes the procedure results as well as the physical properties of the Loire sand.

Three gauged boxes are used to check the homogeneity of the sand column. They are placed at $10 \mathrm{~cm}, 40 \mathrm{~cm}$ and $70 \mathrm{~cm}$ from the column bottom. According to the density index, we could classify the Loire sand procedures (Fig. 3) in 3 categories: weak density sand (A): $0<I_{d}<35 \%$, medium density sand (B and $\mathrm{C}$ ): $35<I_{d}<65 \%$, dense sand (D and $\mathrm{E}$ ): $I_{d}>65 \%$.

Table 5

Viscosity, shear threshold and practical duration of use of the 3 grouts

\begin{tabular}{lllll}
\hline Grout & W/C & Viscosity (mPa.s) & Shear threshold $(\mathrm{Pa})$ & PDU (mn) \\
\hline 1 & 3.57 & 4.15 & 0.07 & 50 \\
2 & 2.38 & 4.83 & 0.22 & 32 \\
3 & 1.78 & 6.80 & 0.54 & 20 \\
\hline
\end{tabular}




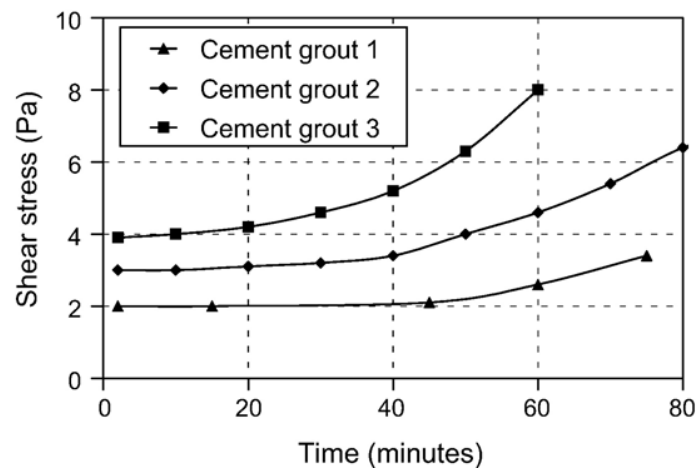

Fig. 5. Shear stress vs. time for the grouts $1,2,3$.

\subsection{Water conductivity results}

Table 4 gives the achieved permeability measurements. The permeability values found in this work are very close to those found by Yin [10]. Thus, we can conclude that the densification procedures for the sand installation in Plexiglas columns have been validated.

\subsection{Grout rheology}

It is necessary to know the grout behavior law before injection. These curves show a shearing threshold for various grout compositions where some parameters are changed (W/C ratio, plasticizer amount, time, temperature...). These clearly show that the Newton model does not fit the grout behavior well, however Bingham's law can be used for such fluids.

\subsubsection{Gradient shear influence on viscosity}

The evolution of viscosity according to shear rate for the three grouts 1, 2 and 3 is presented in Fig. 4. This curve shows that the viscosity increases quickly, then stabilizes. The grout viscosities are deduced from the end part of the curves. Table 5 summarizes the viscosity values at $20{ }^{\circ} \mathrm{C}$ temperature, $2 \mathrm{~min}$ after preparation. The grout 3 injection in the granular matrix can be difficult because of its higher viscosity.

\subsubsection{Temperature and Time influence}

As is well known, temperature increase of the grout makes it more fluid. This was verified for all the grouts studied. To evaluate the grout setting times, measurements of viscosity over
Table 6

The injections carried out

\begin{tabular}{llll}
\hline Injection & $\gamma\left(\mathrm{KN} / \mathrm{m}^{3}\right)$ & $\mathrm{W} / \mathrm{C}$ & Flow $(1 / \mathrm{min})$ \\
\hline Column 1 & 17.06 & 2.38 & 0.33 \\
Column 2 & 17.71 & 2.38 & 0.33 \\
Column 3 & 17.80 & 1.78 & 0.33 , then 0.77 \\
Column 4 & 18.03 & 2.38 & 0.33 \\
Column 5 & 18.28 & 2.38 & 0.33 \\
\hline
\end{tabular}

periods between 2 and $90 \mathrm{~min}$ are done. Fig. 5 gives the evolution of shear stress versus time at $20^{\circ} \mathrm{C}$ temperature, for the three grouts studied with a gradient shear of $585 \mathrm{~s}^{-1}$. This study allows us to determine the practical duration of use (PDU). In addition, the grout stability was checked for this PDU. The values of the PDU are presented in Table 5.

\subsubsection{Plasticizer and Inert load influence}

Some studies [14] have shown that plasticizer also decreases the shearing threshold. However, the plastic viscosity of the cement paste is not affected. Here it is shown that the super plasticizer significantly affects the shear stress and the grout viscosity (Fig. 6). When the super plasticizer quantity is doubled, the viscosity of the grout decreases by $25 \%$. Fig. 11 also shows that viscosity increases with the inert load. Using an optimal quantity of chalk allows us to stabilize the grout and also to ensure good penetrability in the injected ground.

\subsection{Injection results}

During this research project, we carried out several injection tests aiming to understand the phenomenon of filtration. We chose two grouts of relatively low W/C ratio (2.38 and 1.78). We also used high densities of sand ranging between 17.2 and $18.3 \mathrm{kN} / \mathrm{m}^{3}$. Two injection flows were also used $(0.33 \mathrm{l} / \mathrm{min}$ and $0.77 \mathrm{l} / \mathrm{min}$ ). Table 6 summarizes the injections which were made successfully.

The data acquisition has been made for the values of pressure detected by the four sensors. The curves obtained for the injection by water are illustrated in Fig. 7. The four pressure curves present strong slopes for a time period close to $350 \mathrm{~s}$. This phase is followed by stabilization when the pressure approaches $80 \mathrm{kPa}$ for the pressure sensor P1. This clearly shows that after saturation the pressure in all the columns is stabilized.

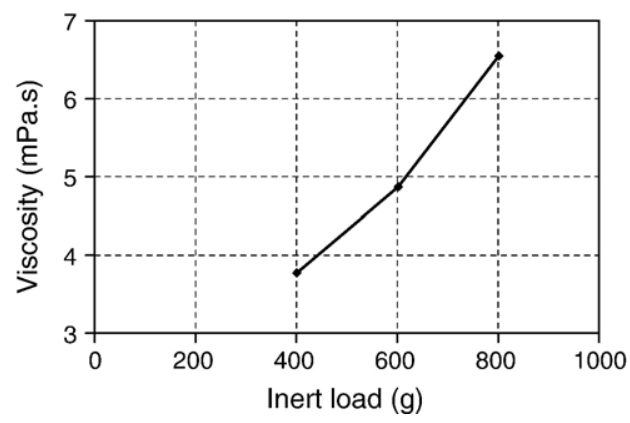

Fig. 6. Plasticizer and inert load effect on the viscosity of grout 2 . 
(a)

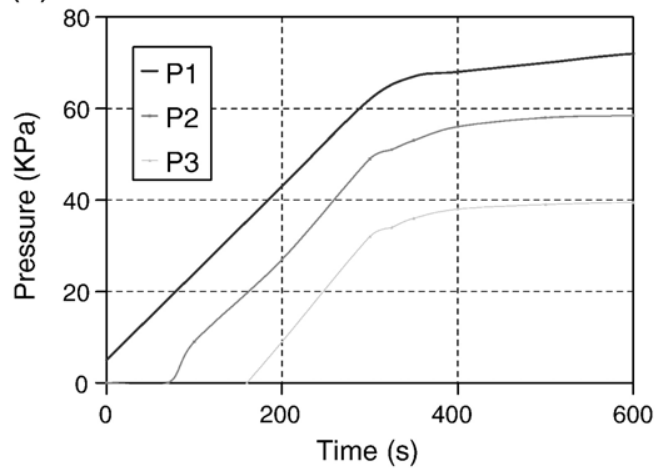

(c)

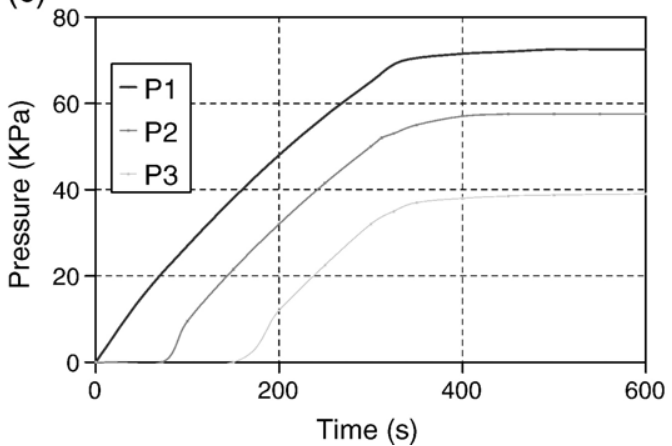

(b)

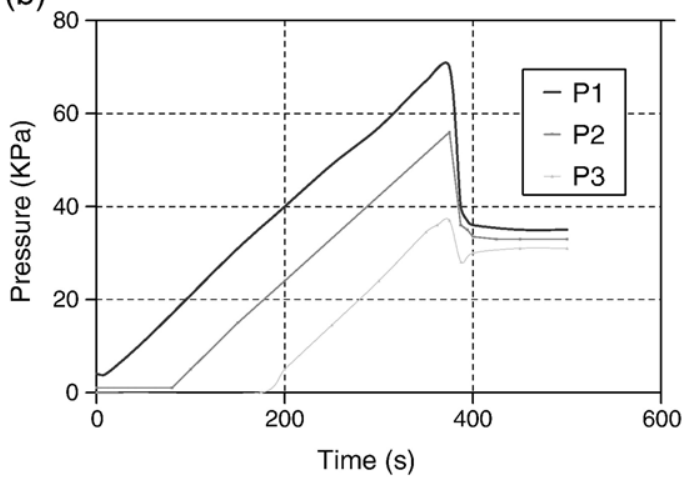

(d)

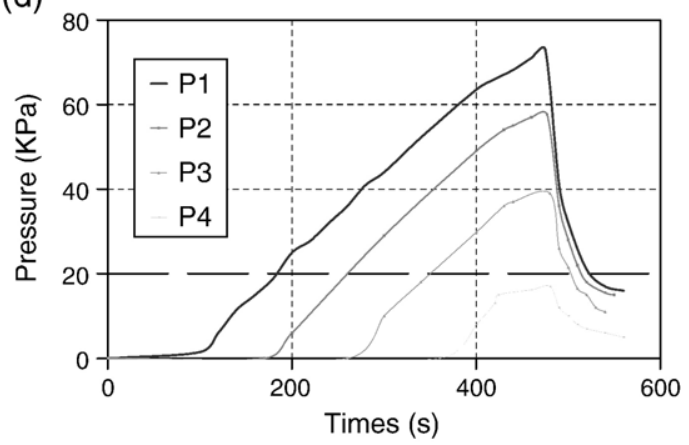

Fig. 7. Pressure evolution during water injection: column no. (a) 2, (b) 3, (c) 4 and (d) 5 .

The pressure evolution in cement grout injection is recorded (Fig. 8). These curves show that, the pressure increases gradually without reaching stabilization, contrary to water. This is due to the increase of the solid quantity of the chalk and cement particles trapped in the granular matrix porosities. It may be noted that the grout saturation time can be detected from these graphs. Indeed, this time corresponds to an abrupt fall, followed by an increase of the pressure. The upper surface of the grout front is, in fact, a zone of mixture about $15 \mathrm{~cm}$ height, characterized by a color progressing from dark to light grey (Fig. 9).

\subsection{Results of gas permeability}

\subsubsection{Flow mode verification}

Checking if the flow mode is laminar allows conformity with the assumptions imposed by the Klinkenberg approach. While
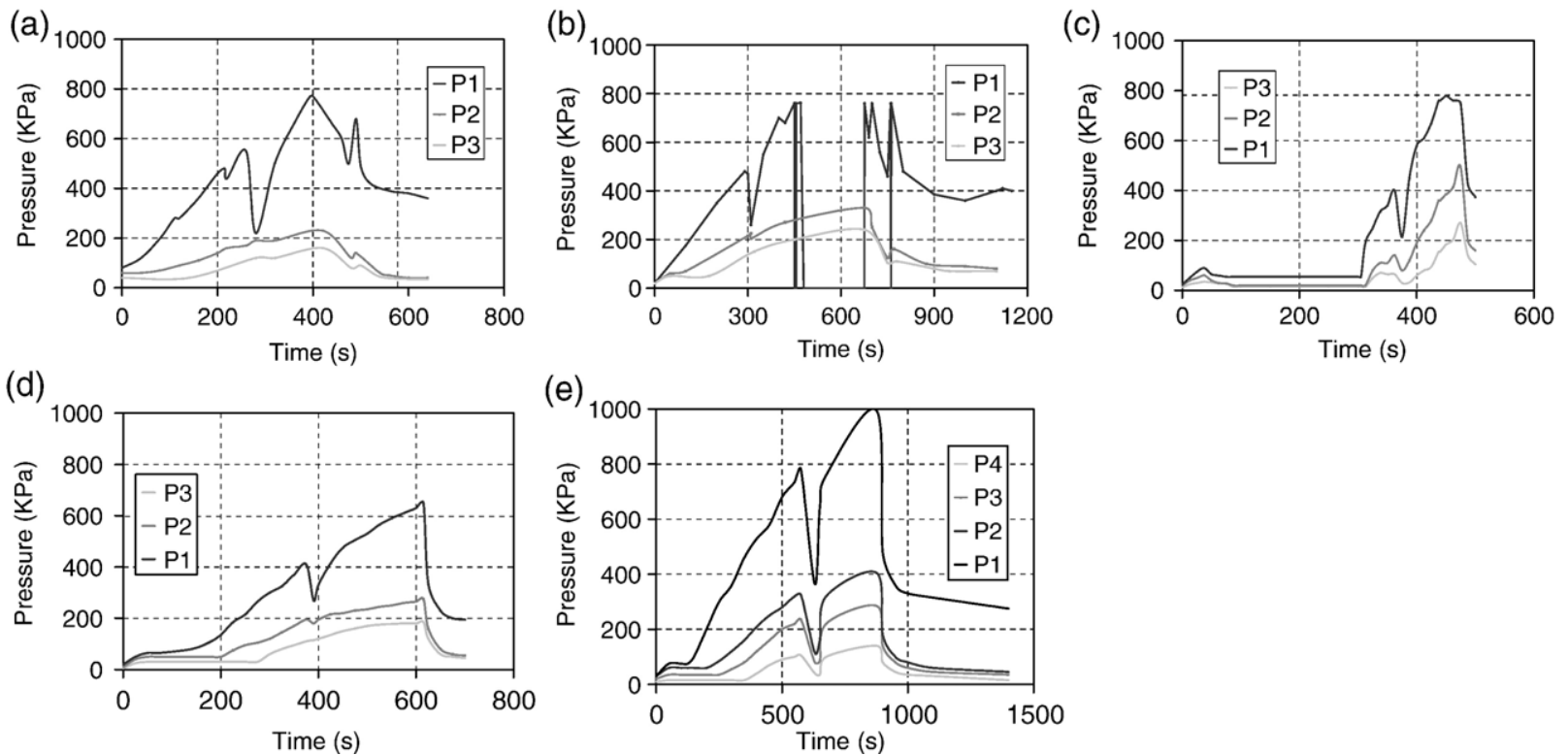

Fig. 8. Pressure evolution versus time during cement grout injection: column (a) 1, (b) 2, (c) 3, (d) 4, (e) 5 . 
(a)

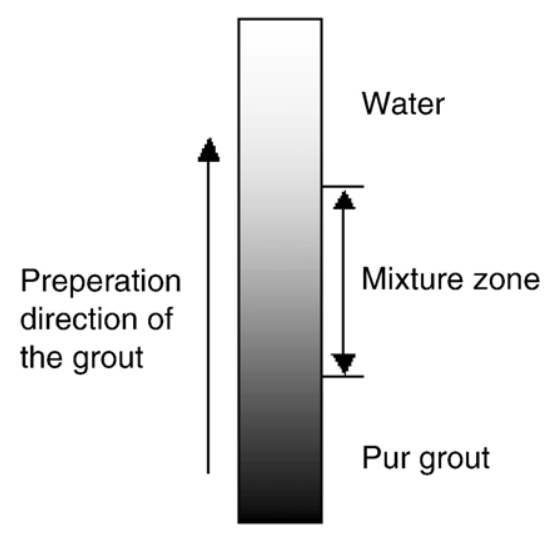

(b)

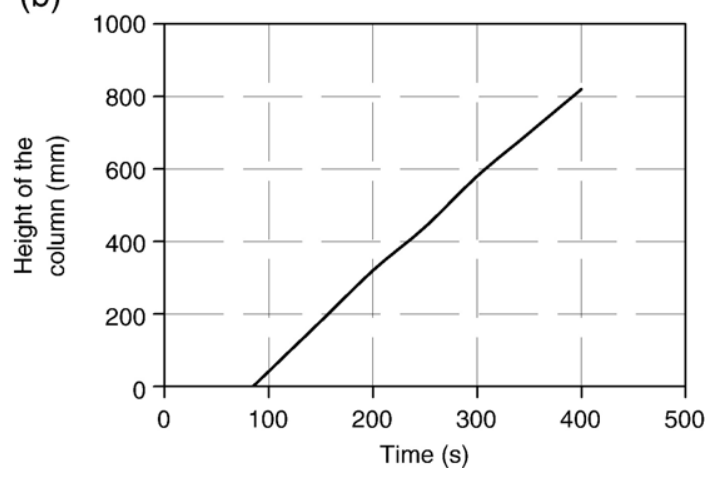

Fig. 9. (a) Schematic grout propagation in the injected column (front advance), (b) Water front propagation versus time for the 5 th injection.
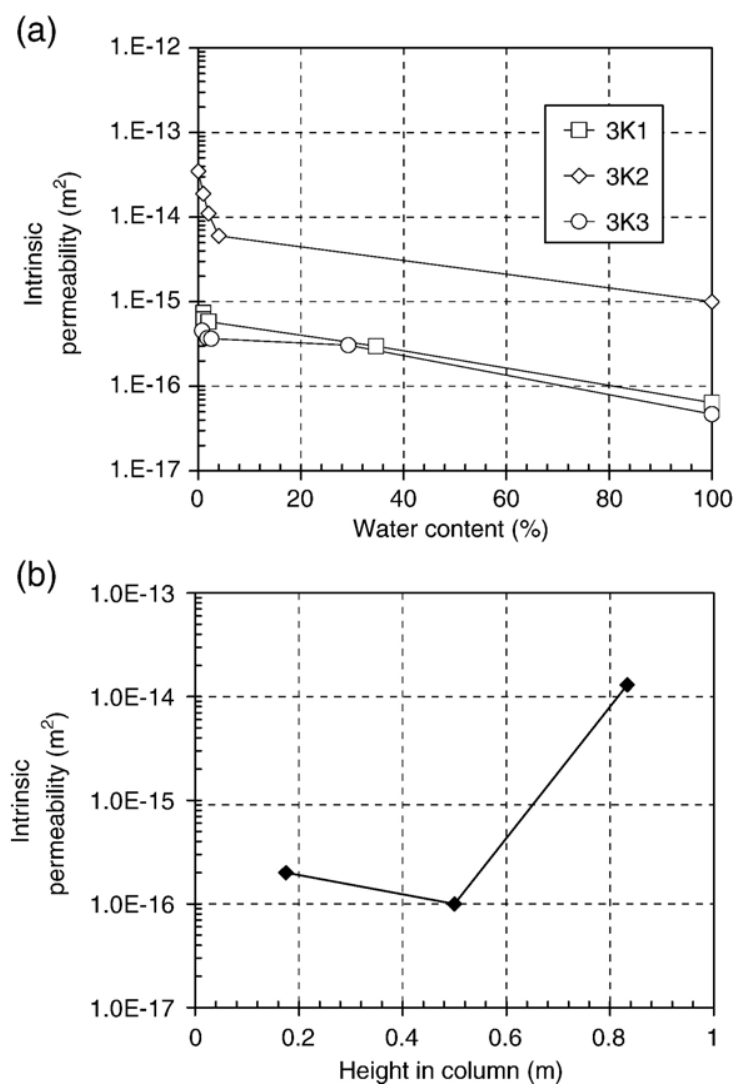

Fig. 10. Permeability evolution vs: (a) water content, (b) : height of the column (column 3).
Table 7

Various injected column permeabilities after setting 1 is from $0-30 \mathrm{~cm}, 2$ between 30 and $60 \mathrm{~cm}$ and 3 is in the $60-90 \mathrm{~cm}$ from the column bottom

\begin{tabular}{|c|c|c|c|c|c|c|c|c|}
\hline \multirow[t]{2}{*}{ Injection } & \multicolumn{2}{|l|}{ I } & \multicolumn{3}{|l|}{$\mathrm{J}$} & \multicolumn{3}{|l|}{$\mathrm{K}$} \\
\hline & 1-I & $2-\mathrm{I}$ & $2-\mathrm{J}$ & $3-\mathrm{J}-1$ & $3-\mathrm{J}-2$ & $1-\mathrm{K}-1$ & $1-\mathrm{K}-2$ & $2-\mathrm{K}-1$ \\
\hline $\begin{array}{l}\text { Permeability } \\
\left(\mathrm{m}^{2}\right)\end{array}$ & $\begin{array}{l}3.59 \\
10^{-16}\end{array}$ & $\begin{array}{l}2.75 \\
10^{-13}\end{array}$ & $\begin{array}{l}4.08 \\
10^{-15}\end{array}$ & $\begin{array}{l}1.57 \\
10^{-15}\end{array}$ & $\begin{array}{l}2.27 \\
10^{-15}\end{array}$ & $\begin{array}{l}1.97 \\
10^{-16}\end{array}$ & $\begin{array}{l}1.55 \\
10^{-16}\end{array}$ & $\begin{array}{l}1.47 \\
10^{-16}\end{array}$ \\
\hline \multirow[t]{2}{*}{ Injection } & \multicolumn{3}{|l|}{ L } & M & $\mathrm{N}$ & & & \\
\hline & $1-\mathrm{L}$ & $2-\mathrm{L}$ & $3-\mathrm{L}$ & $3-\mathrm{M}-1$ & $1-\mathrm{N}$ & $2-\mathrm{N}-1$ & $2-\mathrm{N}-2$ & $3-\mathrm{N}$ \\
\hline $\begin{array}{l}\text { ermeability } \\
\left(\mathrm{m}^{2}\right)\end{array}$ & $\begin{array}{l}2.96 \\
10^{-15}\end{array}$ & $\begin{array}{l}6.23 \\
10^{-15}\end{array}$ & $\begin{array}{l}5.59 \\
10^{-15}\end{array}$ & $\begin{array}{l}5.28 \\
10^{-15}\end{array}$ & $\begin{array}{l}3.26 \\
10^{-15}\end{array}$ & $\begin{array}{l}1.80 \\
10^{-14}\end{array}$ & $\begin{array}{l}8.67 \\
10^{-15}\end{array}$ & $\begin{array}{l}1.75 \\
10^{-14}\end{array}$ \\
\hline
\end{tabular}

analyzing the apparent permeability curve, it is necessary to check that the streamline flow is properly verified.

\subsubsection{Permeability evolution versus water content}

The gas permeability of a water saturated sample cannot be measured $[23,24]$. A partial drainage is thus necessary. The drying mode and the degree of saturation of the sample influence the gas permeability. Fig. 10.a shows a progressive increase in the permeability with the sample water content reduction. The $3 \mathrm{~K} 1$ sample permeability presents a slope which is not as steep as that of $3 \mathrm{~K} 3$. This is due to the $3 \mathrm{~K} 3$ sample initial state which seems to be less hydrated than $3 \mathrm{~K} 1$.

\subsubsection{Permeability variation according to the height in the column}

Permeability tests were carried out on several heights in the injected columns. As the columns are injected by the bottom, we expect to have more filtration in this section and lower permeability than those in the column middle and top.

The permeability variation in the same section can be explained as follows: during the installation of sand in the column by $10 \mathrm{~cm}$ layers compaction, segregation is created and can be seen through the walls of the column (Fig. 10. b). The part separating 2 layers has a high porosity and consequently will be more loaded with grout. The sample $3 \mathrm{~K} 2$ is taken from this separating zone. This can explain its strong permeability compared to the other samples. Table 7 summarizes the average values of permeabilities obtained for the various columns.

\section{Discussion and Interpretation}

\subsection{Sand Column preparation and Darcy permeability}

The sand homogeneity in the columns and in the permeameter is difficult to obtain. Nevertheless, the densification by layers method remains good and suitable for materials like Loire sand (containing relatively big shelly remains) if applied with care. The results obtained in terms of densities and permeabilities to water (constant load permeameter) are satisfactory. 

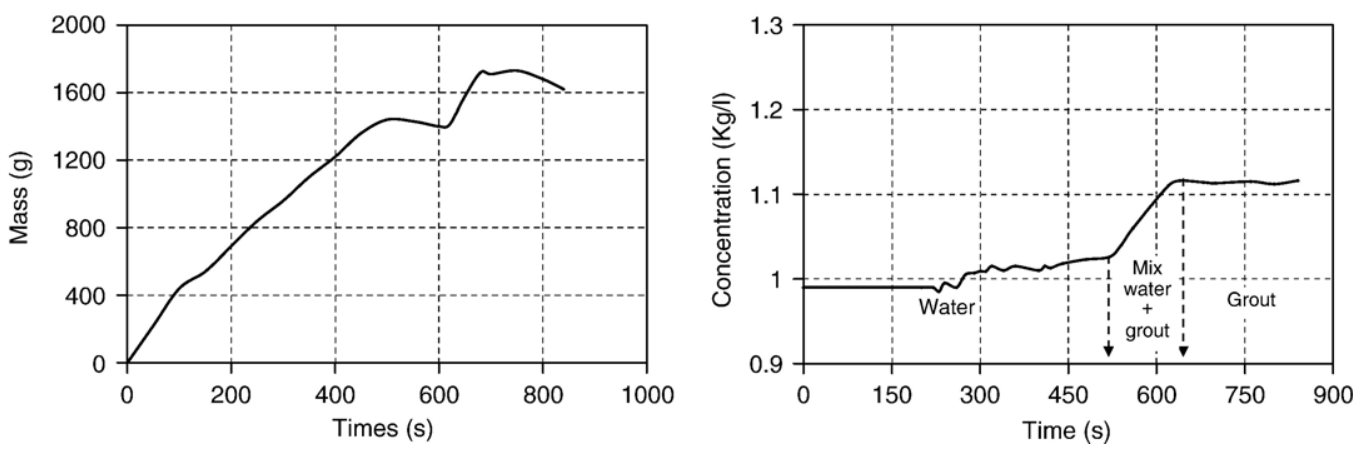

Fig. 11. Column mass and fluid volumetric mass evolution (out of the column test) versus time (injection5).

\subsection{Column mass evolution, and fluid density during cement grout injection}

The mass of the liquid leaving the top of the column is recorded according to time. This mass evolution enables us to follow the column mass evolution. The water volume leaving the column is assumed to be equal to the grout volume entering it.

Fig. 11 presents the column mass and the fluid density evolution according to time, between 0 and $900 \mathrm{~s}$. In this figure, we distinguish three intervals. From 0 to $490 \mathrm{~s}$ : an increase in the column mass at the beginning of the injection which is due to the removal of water present in the granular matrix by the grout. Thus the fluid density curve has a very slight slope. At the beginning, the column mass evolution is due to the difference in density between the grout and water. From $490 \mathrm{~s}$ to $620 \mathrm{~s}$ : there is a stage indicating the saturation of the column with grout where the mass is stabilized. At the same time, grout traces start to be detected in water at the exit of the column. Beyond $620 \mathrm{~s}$ : the mass increases again, because of the filtration of solid grout particles by the granular matrix pores. The stabilization of the density curve indicates that only pure grout is exiting from the column.

The time during which we record a mixture (water and grout) can be related to the height of the grout front advance in the column.

\subsection{Comparison between water and gas permeability}

As shown in the results section, three parameters are important for gas permeability: height in the column, water content,

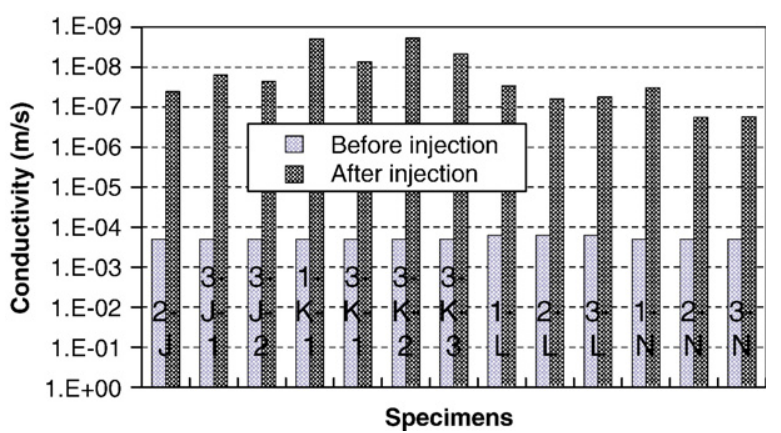

Fig. 12. Permeability decrease after injection. ( 1 is from $0-30 \mathrm{~cm}, 2$ between 30 and $60 \mathrm{~cm}$ and 3 is in the $60-90 \mathrm{~cm}$ from the column bottom same presentation as Table 7). and sand density-W/C ratio. In order to compare the water permeability values presented before, to those obtained by gas, we will determine the apparent permeability values $K$ (in $\mathrm{m} / \mathrm{s}$ ), which depend on the viscosity of the fluid starting from Poiseuille's law: $K(\mathrm{~m} / \mathrm{s})$

$K(m / s)=k\left(m^{2}\right) \frac{\rho g}{\mu}$

With: $\rho$ : fluid volumetric mass, and $\mu$ : the dynamic viscosity of the fluid.

In Fig. 12, the comparison between permeabilities before and after the injection for all the tested samples is presented (using Eq. (3) for conversion). This figure shows the strong reduction of permeability after grout injection. The reduction coefficient is between $10^{-3}$ and $10^{-5}$. This can help to evaluate the improvement in the soil during reinforcement operations by grouting procedures.

\section{Conclusion}

In this paper, we studied grout propagation in an injected medium (Loire sand) requiring a characterization, as well as the grout used. The densification procedures allowed us to obtain porosity values ranging between 0.4 and 0.3 . The obtained permeabilities to water are comprised between 1.5 and 2.5 $10^{-4} \mathrm{~m} / \mathrm{s}$ for the highest densities. The grout rheological behavior (Bingham law) and all parameter influences are known before injection tests are carried out. It was shown that the grout advances in granular medium with a front zone of $25-30 \mathrm{~cm}$. Measurements of pressure, fluid mass and column mass evolution according to time are analyzed and the filtration phenomenon is highlighted and explained.

In order to evaluate the injection contribution on the porosity reduction, permeability to gas measurements allow us to follow the changes in the medium according to water content, sand density, and $\mathrm{W} / \mathrm{C}$ ratio. The obtained permeability values range between $10^{-13} \mathrm{~m}^{2}$ and $10^{-16} \mathrm{~m}^{2}$.

This strong decrease is not easy to quantify because of the complexity of the studied medium. Indeed the variation of only one parameter such as the sand density can significantly change the permeability. A study of permeability according to the saturation degree of other samples is necessary in order to study more closely the effect of water saturation on injected media reinforcement. 


\section{Acknowledgements}

The assistance of Pr. AGHALIAS, from the Saint-Nazaire Technical Institute (LG.PEA, C.R.T.T.), who put the rheometer at our disposal, is sincerely appreciated.

\section{References}

[1] L. Jason, N. Saiyouri, P.Y. Hicher, Numerical study of propagation grout in sands, 4th international conference on ground improvement techniques, Kuala Lumpur, Malaysia, March 26-28 2002, pp. 437-444.

[2] N. Saiyouri, Experimental study and modelling of the grout propagation in porous media, Review article, numerical modelling of 2 and 3 phases. ECN Report for RGCU/Intra for, 2002 (in French).

[3] Z. Saada, J. Canou, L. Dormieux, J.C. Dupla, S. Maghous, Modelling of cement grout suspension flow in granular porous media, International Journal of Numerical and Analytical Methods in Geomechanics 29 (2005) 691-711.

[4] F. Bouchelaghem, L. Vulliet, D. Leroy, L. Laloui, F. Descouerdes, Real-scale miscible grout injection and performance of advection-dispersion-filtration model, International Journal of Numerical and Analytical Methods in Geomechanics 25 (2001) 1149-1173.

[5] G. Azzar, Modélisation des injections de coulis de Bentonite Ciment dans les sols, PhD Thesis, ENSAM, France, 1997.

[6] A. Einstein, Eine neue Bestimmung der Moleküldimensionen, Annalen der Physik (Leipzig) 19 (1906) 289-306.

[7] E. Guth, R. Simha, Kolloid Zheitung 74 (1936) 266.

[8] H.C. Brinkman, The viscosity of concentrated suspensions and solutions, Journal of Chemical Physics 20 (4) (1952) 571

[9] M. Bouasker, N. Saiyouri, A. Khelidj, Characterization of an injected sand with cement grout by gas permeability measurement, 6th Conference on Ground Improvement Techniques, Coimbra, Portugal, July 18-19 2005.

[10] Z. Yin, Study of the injected grout with ultra fine cement, Research Master, ECN, , 2004 (in French).

[11] Norme de perméabilité à l'eau NFP 94-090-1, Reconnaissance et essais géotechniques-Essais de laboratoire sur les sols-Partie 11, Détermination de la perméabilité au perméamètre à charge constante ou variable, ISO/TS 7892-11, 2004.

[12] D. Ciceron, Fluidisation of various shaped particles by non-newtonian liquids, PhD Thesis, University of Nantes, France, 2000.

[13] C.S.R.P.P.G.N, (Chamber of research and production of oil and natural gas), rheological handbook of the drilling fluids and cement slag (in French).

[14] P.F.G. Banfill, Rheology of Fresh Cement and Concrete, E \&FN Spon, London, 1991.

[15] S. Candel, Run of fluid mechanics, DUNOD edition, Paris, 1st edition, 1999.

[16] F. Rosquoët, A. Alexis, A. Khelidj, A. Phelipot, Experimental study of cement grout: rheological behaviour and sedimentation, Cement and Concrete Research 33 (2003) 713-722.

[17] O. Chupin, N. Saiyouri, P.Y. Hicher, Numerical modelling of cement grout injection in saturated porous media, 16Th ASCE Engineering Mechanics Conference, University of Washington, Seattle, July 16-18, 2003.

[18] O. Chupin, N. Saiyouri, P.Y. Hicher, Cement Grout Injection Tests in Tanks: experiments and modelling, 5Th European Solid Mechanics Conference, University of Tessalonique Grèce, August 17-22, 2003

[19] J.J. Kollek, The determination of the permeability of concrete to oxygen by the Cembureau method - a recommendation, Materials and Structures 22 (1989) 225-230.

[20] V. Picandet, A. Khelidj, G. Bastian, Effect of axial compressive damage on gas permeability of ordinary and high-performance concrete, Cement and Concrete Research 31 (2001) 1525-1532.

[21] AFREM, groupe durabilité des bétons "mode opératoire recommandé, essai de perméabilité au gaz du béton durci », compte rendu des journées techniques AFPC-AFREM, durabilité des bétons, «méthodes recommandées pour la mesure des grandeurs associées à la durabilité ", Toulouse, 11-12 décembre, 1997, pp. 125-134.

[22] M.P. Yssorche, The self dessiccation microcracking and durability of HPC and UHPC, Materials and Structures 32 (1999) 14-21.

[23] A. Abbas, M. Carcasses, J-P. Ollivier, Gas permeability of concrete in relation to its degree of saturation, Materials and Structures 32 (1999) 3-8.

[24] E. Nicollini, R. Nova, Modelling of a tunnel excavation in a non cohesive soil improved with cement mix, Computers and Geotechnics 27 (2000) 279-272fs. 